\title{
Public Health England's capture by the alcohol industry
}

\author{
Those that fail to learn from history are doomed to repeat it
}

\author{
Ian Gilmore professor of medicine ${ }^{1}$, Linda Bauld professor of health policy ${ }^{2}$, John Britton professor \\ of epidemiology ${ }^{3}$
}

${ }^{1}$ University of Liverpool, Liverpool, UK; ${ }^{2}$ University of Stirling, Stirling, UK; ${ }^{3}$ University of Nottingham, Nottingham, UK

As in many rich countries, public health in the United Kingdom is blighted by harms caused by consumption of unhealthy commodities such as tobacco, alcohol, and foods high in fat, sugar, or salt. ${ }^{1}$ In England, responsibility for tackling these problems lies with Public Health England (PHE), an executive branch of the Department for Health and Social Care. ${ }^{2}$

It is a challenging task: consumption of these commodities is driven by powerful transnational companies ${ }^{3}$ with a history of cooperation in opposing health legislation and adopting similar tactics to influence and restrict controls on their market environments. ${ }^{4}$ The launch on 10 September of a health promotion partnership ${ }^{5}$ between PHE and Drinkaware, an organisation that is funded by the alcohol industry, indicates that PHE is struggling to rise to the challenge.

Commercial companies survive by profiting from the things they produce, and for those producing tobacco, alcohol, or unhealthy foods, that profit motive inevitably runs counter to health. These industries have adopted common and successful strategies to prevent, undermine, dilute, or constrain measures designed to curtail their activities. Their actions include a focus on personal responsibility for health harms; championing the rights of the individual to adopt unhealthy behaviours as a matter of personal freedom; attacking critics; dismissing research findings as "junk science"; funding alternative research that provides pro-industry results; investing in corporate social responsibility activities to enhance reputation; mounting legal challenges; and, crucially, opposing and avoiding effective health regulation by promoting voluntary codes and partnerships with government. ${ }^{46}$

The lesson from tobacco is that for most of the second half of the 20th century the UK government acceded to these approaches, entering into a series of voluntary agreements and codes of practice on tobacco advertising that not only permitted advertising to continue for over half a century but culminated in some of the country's most iconic advertising campaigns. ${ }^{7}$ The Public Places Charter established with the hospitality industry in $1998^{8}$ delayed the introduction of comprehensive smoke-free legislation by nearly a decade; and the promotion of low tar cigarettes sustained smoking for decades through smokers' mistaken belief that they presented a lower health risk. $^{9}$

The consequence of these and other policy failures is that we still have millions of smokers in the UK, instead of thousands. By entering into a voluntary agreement with Drinkaware, PHE seems to have fallen victim to the delusion that a new partnership with the alcohol industry will somehow avoid the same fate.

Although PHE describes it as an independent educational charity, ${ }^{5}$ Drinkaware's website confirms that the organisation is funded by donations from UK alcohol producers, retailers, and supermarkets, with the aim to "reduce alcohol-related harm by helping people make better choices about their drinking." 10 The press release for the new campaign encourages people to have "more alcohol-free days a week" (PHE quote) and "few alcohol-free days" (Drinkaware quote), ${ }^{5}$ following the historical strategy of defining the problem in terms of the minority of people who drink every day. The press release does not make direct reference to harmful levels of drinking on other days of the week, or endorse the UK chief medical officers' advised upper limit of 14 units a week for both sexes. ${ }^{11}$ The campaign is badged as part of the broader One You campaign, which includes advice on smoking, physical activity, and other lifestyle determinants of health, thus linking an industry funded body with wider health messaging.

\section{What does the alcohol industry have to gain?}

The question that senior PHE managers do not seem to have asked themselves in the process of entering into this partnership, and certainly did not ask their alcohol leadership advisory board, is why the alcohol industry is happy to fund a campaign that ostensibly aims to reduce alcohol consumption. Had they done so they would have received the answer that the industry does so because it thinks the campaign will be ineffective or will divert attention from other more effective policies to reduce alcohol consumption that the industry fears more, such as minimum unit pricing. 
More importantly, however, through Drinkaware, the alcohol industry gains valuable engagement with PHE, establishes working relations with PHE staff, and may even secure a seat at the table when other alcohol harm initiatives are planned and executed. In so doing they tread a path that, at least to those who have worked in tobacco policy, is depressingly familiar. It is right that the alcohol and other harmful commodity industries pay to prevent and treat harm caused by their products, but payment must be made through statutory levies not voluntary agreements. To paraphrase Aldous Huxley, the most important of all the lessons of history is that people do not learn very much from them. The leadership of PHE would be well advised to start learning now.

Competing interests: We have read and understood BMJ policy on declaration of interests and declare the following interests: IG has given a paid lecture for Kyowa Kirin, the manufacturer of Pabrinex vitamin $B$ and $C$ injection. $\mathrm{He}$ is chair of the Alcohol Health Alliance and resigned recently as co-chair of the alcohol leadership board, Public Health England. JB is director of the UK Centre for Tobacco and Alcohol Studies, a member (and former chair) of the Royal College of Physicians tobacco advisory group, and a member of the board of trustees of Action on Smoking and Health. He co-chairs the PHE tobacco control implementation board. LB is deputy director of the UK Centre for Tobacco and Alcohol Studies, holds the CRUK/BUPA chair in behavioural research for cancer prevention at Cancer
Research UK, is a trustee of the Institute of Alcohol Studies, and a member of the PHE tobacco control implementation board.

Provenance and peer review: Commissioned; not externally peer reviewed.

1 Murray CJ, Richards MA, Newton JN, etal . UK health performance: findings of the Global Burden of Disease Study 2010. Lancet 2013;381:997-1020.

10.1016/S0140-6736(13)60355-4 23668584

2 Public Health England. About us. https://www.gov.uk/government/organisations/publichealth-england/about.

3 Moodie R, Stuckler D, Monteiro C, etal. Lancet NCD Action Group. Profits and pandemics: prevention of harmful effects of tobacco, alcohol, and ultra-processed food and drink industries[doi]. Lancet 2013;381:670-9. 10.1016/S0140-6736(12)62089-3. 23410611

4 Gilmore AB, Savell E, Collin J. Public health, corporations and the new responsibility deal: promoting partnerships with vectors of disease? J Public Health (Oxf) 2011;33:2-4. 10.1093/pubmed/fdr008 21289060

5 Public Health England. Public Health England and Drinkaware launch Drink Free Days. 2018. https://www.gov.uk/government/news/public-health-england-and-drinkaware-launchdrink-free-days

6 Bauld L. Funders must be wary of industry alliances. Nature 2018;560:283. 10.1038/d41586-018-05937-w 30108358

7 Hastings G, MacFadyen L. Keep smiling no one's going to die. 2000. http://www. tobaccopapers.com/keepsmiling/KeepSmilingReport.pdf

8 Department of Health. Smoking kills. A white paper on tobacco. Stationery Office, 1998. National Cancer Institute. Smoking and tobacco control monograph 13: risks associated with smoking cigarettes with low tar machine-measured yields of tar and nicotine. 2001. https://cancercontrol.cancer.gov/brp/tcrb/monographs/13/

10 Drinkaware. About us. https://www.drinkaware.co.uk/about-us/

11 Department of Health, Welsh Government, Department of Health Northern Ireland, Scottish Dovernment. UK chief medical officers low risk drinking guidelines. 2016. https://assets. ublishing service govuk

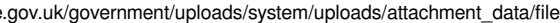
545937/UK_CMOs_report.pdf

Published by the BMJ Publishing Group Limited. For permission to use (where not already granted under a licence) please go to http://group.bmj.com/group/rights-licensing/ permissions 